\title{
STOICHIOMETRY OF THE REACTION OF A POTASSIUM-ARSENIC JAROSITE IN NaOH MEDIUM
}

\author{
${ }^{1}$ Francisco PATIÑO CARDONA, ${ }^{2}$ Mizraim Uriel FLORES GUERRERO, \\ ${ }^{3,4}$ Iván Alejandro REYES DOMÍNGUEZ, 5 Julio César JUÁREZ TAPIA, ${ }^{5}$ Martín REYES PÉREZ, \\ ${ }^{5}$ Hernán ISLAS \\ ${ }^{1}$ Universidad Politécnica Metropolitana de Hidalgo, Ingeniería en Energía, México, \\ franciscopatinocardona@gmail.com \\ 2Universidad Tecnológica de Tulancingo, Área de Electromecánica Industrial, México \\ ${ }^{3}$ CONACYT-Consejo Nacional de Ciencia y Tecnología, México \\ ${ }^{4}$ Universidad Autónoma de San Luis Potosí, Instituto de Metalurgia, México \\ ${ }^{5}$ Universidad Autónoma del Estado de Hidalgo, Área Académica de Ciencias de la Tierra y Materiales, \\ México
}

https://doi.org/10.37904/metal.2021.4214

\begin{abstract}
The jarosite sample was subjected to characterization by dichromatometry, gravimetric analysis, XRD, AAS, ICP, SEM and EDS. The particles of this compound are spherical and made up of rhombohedral microcrystals. The density of potassium jarosite with arsenic was $2890 \mathrm{~kg} / \mathrm{m}^{3}$. The synthesis study of this compound indicated that $\mathrm{AsO}_{4}$ replaced $\mathrm{SO}_{4}$, thus forming arsenic jarosite. Such replacement makes of jarosites potential compounds for the stabilization of arsenic. The S-shaped decomposition curve of potassium jarosite with arsenic in $\mathrm{NaOH}$ media showed a modest induction period, a progressive conversion period and a stabilization zone which indicates that the reaction has ended. Through alkaline reactivity studies we observed that $\mathrm{SO}_{4}{ }^{2-}$ and $\mathrm{K}^{+}$diffuse from the arsenic jarosite particle into the solution, and at the same time $\mathrm{OH}^{-}$diffuses from the bulk of the solution into the core of arsenic jarosite particles. The result of this process is that $\mathrm{Fe}, \mathrm{As}$ and $\mathrm{O}$ remain distributed throughout the particle, forming an amorphous gel of iron hydroxide with absorbed arsenic. This arsenic-rich gel does not evolve into crystal phases. Arsenic is retained in this amorphous compound. However, when it is exposed to temperatures in the order of $600{ }^{\circ} \mathrm{C}$, it decomposes, giving $\mathrm{Fe}_{2} \mathrm{O}_{3(\mathrm{~s})}$ and $\mathrm{As}(\mathrm{g})$ as a result.
\end{abstract}

Keywords: Potassium-arsenic jarosite, acid mine drainage, iron hydroxide, amorphous gel, stabilization

\section{INTRODUCTION}

Man first got involved with jarosite-type minerals at around 1200 B.C. in Rio Tinto, Spain, where it is believed that the silver mines of King Solomon were hidden [1]. This mineral has been found in several parts of the world, such as Spain, Peru, and The U.S. among others, as it is an attractive source of silver [1,2]. For instance, in the State of Utah, U.S., ores with values of up to $34 \mathrm{Kg} \mathrm{Ag} /$ tonne have been found [2]. Figure 1 shows the layered distribution of jarosites in Rio Tinto, Spain [3]. Given the nature of jarosites to incorporate Fe in their structure, and given the problems the metallurgical industry has faced when removing $\mathrm{Fe}$ from hydrometallurgical circuits, dozens of researchers have taken the task of establishing a new technology for the precipitation of $\mathrm{Fe}$ by synthesis of jarosites in such circuits [4-6]. All the known members of the jarosite family are represented by the general formula: $\mathrm{MFe}_{3}\left(\mathrm{SO}_{4}\right)_{2}(\mathrm{OH})_{6}$ where $\mathrm{M}^{+}$is $\mathrm{H}_{3} \mathrm{O}^{+}, \mathrm{Na}^{+}, \mathrm{K}^{+}, \mathrm{Rb}^{+}, \mathrm{Ag}^{+}, \mathrm{NH}_{4}^{+}, \mathrm{Tl}^{+}$, $1 / 2 \mathrm{Hg}^{2+}[7]$. $\mathrm{SO}_{4}$ in the general jarosite formula can be partially replaced with $\mathrm{AsO}_{4}$, thus producing arsenical jarosites, such as potassium-arsenic jarosite. The property of jarosites of incorporating arsenic into their 
structure makes them potential media for the removal of this and other toxic elements from the environment. This piece of work is part of a wider study that aims to eliminate arsenic from acid mine drainage, and based on this goal, in this paper we study the stoichiometry of the reaction of potassium jarosite in $\mathrm{NaOH}$ medium in order to determine the reaction products and to observe whether arsenic diffuses into the alkaline solution.

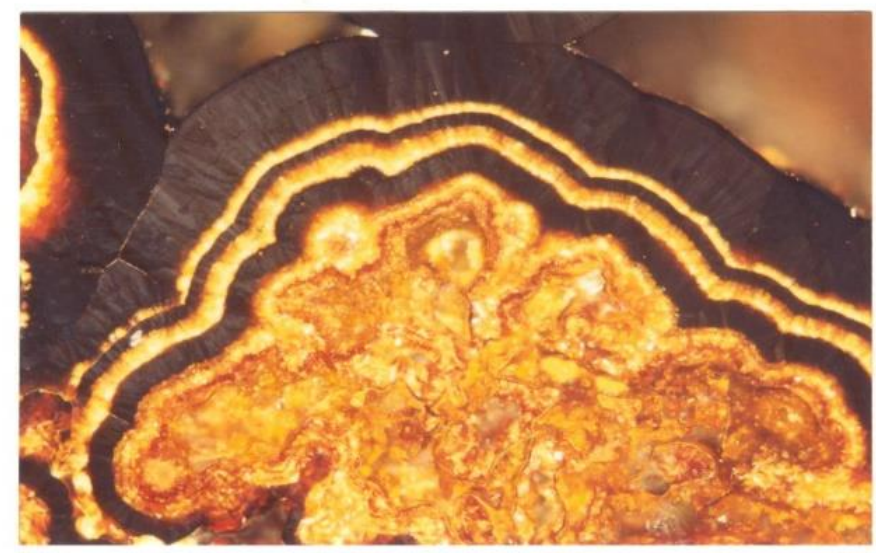

Figure 1 Layered distribution of jarosites in a gossan ore. Polarized light [3]

\section{MATERIALS AND METHODS}

\subsection{Synthesis}

A sample of arsenic jarosite was synthesized following the experimental conditions used by Flores et al. [8]. This compound was characterized by dichromatometry, gravimetric analysis, inductively coupled plasma spectrometry (ICP), atomic absorption spectrophotometry (AAS), X-ray diffraction (XRD), and scanning electron microscopy with energy-dispersive X-Ray spectroscopy (SEM-EDS). The solids of the synthetic arsenic jarosite were filtered and thoroughly washed with hot water $\left(70^{\circ} \mathrm{C}\right)$ to remove $\mathrm{Fe}$ and $\mathrm{AsO}_{4}{ }^{2-}$ residues. They were subsequently dried in a muffle furnace at $70^{\circ} \mathrm{C}$ for 3 hours, then weighed and wet-sieved in order to determine particle size distribution; in addition, their density was determined using a pycnometer.

\subsection{Experimental procedure}

The experimental procedure for the study of the decomposition of arsenic jarosite in $\mathrm{NaOH}$ medium was similar to that used in previous works by Patiño et al. [9]. The alkaline decomposition was conducted in a $0.5 \mathrm{~L}$ glass reaction kettle placed on a hotplate with automatic temperature control and magnetic stirring. $\mathrm{pH}$ of the solution was constantly measured with an Orion $3 \mathrm{Star} \mathrm{pH}$-meter equipped with a Thermo Ross Ultra Sure Flow pH electrode. The study of the reactivity of arsenic jarosite in $\mathrm{NaOH}$ medium was conducted using $0.20 \mathrm{gr}$ of jarosite solid with $38 \mu \mathrm{m}$ particle size in a volume of $0.5 \mathrm{~L}$. The $\mathrm{OH}^{-}$concentration of the working solution was determined by considering the constant of the ionic product of water and the $\mathrm{pH}$ of the alkaline solution at the work temperatures we used [10]. The decomposition process of arsenic jarosite is characterized by the elimination of potassium and sulfate ions from the lattice of this jarosite into the solution. Therefore, the progress of the reaction was monitored by taking $5 \mathrm{ml}$ samples of the solution that were filtered and analysed to determine sulfate concentration by ICP and potassium by AAS. Likewise, residual solid samples were taken at different reaction times and analysed by SEM-EDS and XRD.

\section{RESULTS AND DISCUSSION}

Potassium jarosite incorporated $3.82 \mathrm{wt} \%$ arsenic as arsenate $\left(\mathrm{AsO}_{4}\right)$ in its structure, and it exhibited the following approximate formula:

$$
\left[\mathrm{K}_{0.75}\left(\mathrm{H}_{3} \mathrm{O}\right)_{0.25}\right] \mathrm{Fe}_{1.85}\left[\left(\mathrm{SO}_{4}\right)_{1.82}\left(\mathrm{AsO}_{4}\right)_{0.18}\right]\left[(\mathrm{OH})_{2.34}\left(\mathrm{H}_{2} \mathrm{O}\right)_{3.66}\right]
$$


The density of potassium jarosite with arsenic was $2890 \mathrm{~kg} / \mathrm{m}^{3}$. Figure 2 shows a spherical particle, and Figure 3 shows that the same particle is made up of rhombohedral microcrystals soundly bound in a compact structure. These aspects are fundamental for any study on reactivity and heterogeneous kinetics. In addition, this jarosite is capable of incorporating arsenic from acid mine drainage into its structure, which has positive implications from an environmental point of view. This could minimize problems related to pollution by arsenic contained in liquid waste resulting from mining and metallurgical processes.

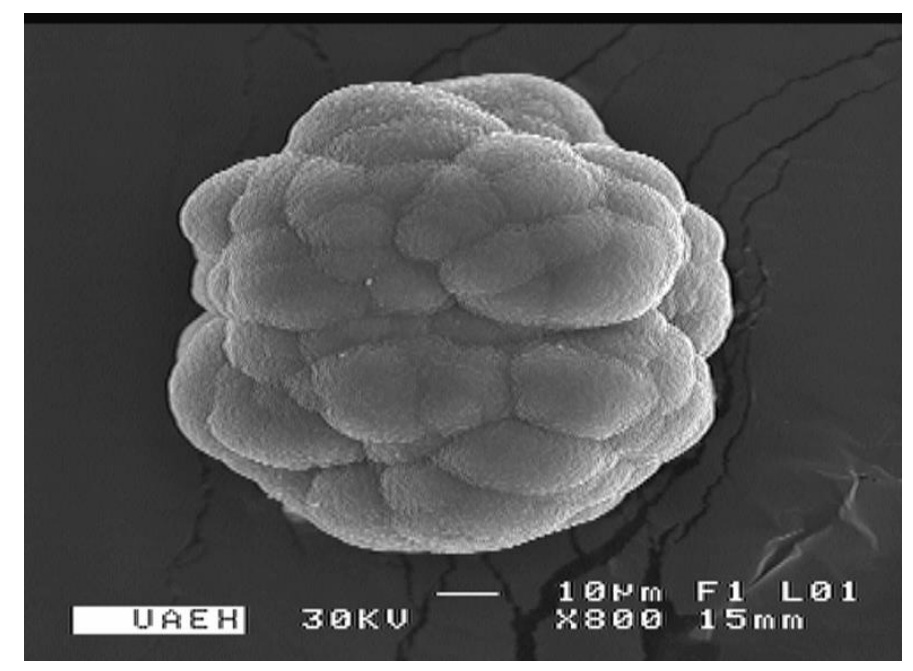

Figure 2 Potassium-arsenic jarosite particle

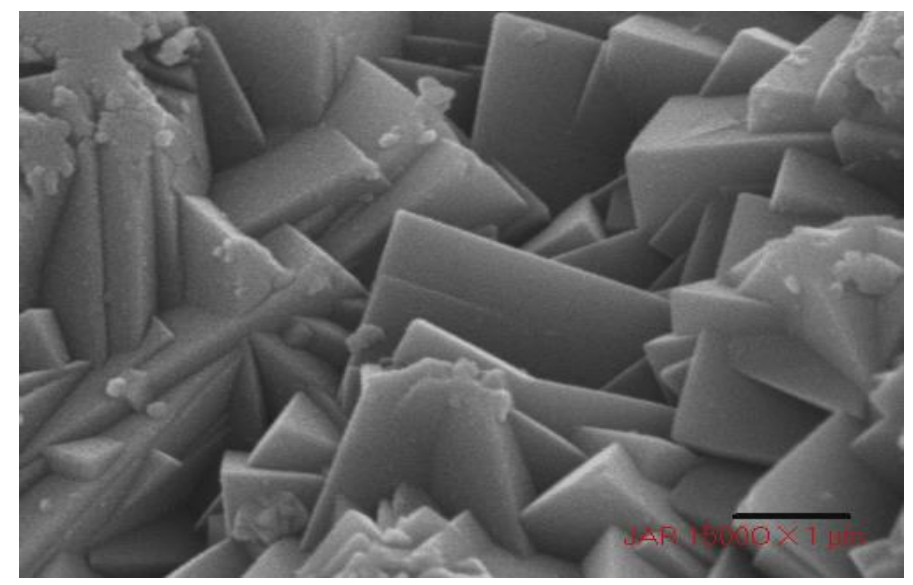

Figure 3 Microcrystals of potassium-arsenic jarosite particles

Figure 4 exhibits the $S$ shaped decomposition curve, which has a modest induction period, a progressive conversion period and a stabilization zone of $\mathrm{SO}_{4}{ }^{2-}$ and $\mathrm{K}^{+}$. Figure 5 shows $\mathrm{X}$-ray diffractograms at different decomposition times of potassium-arsenic jarosite, where it can be observed that the intensities of reflection of the crystal planes decrease until they fade, which is consistent with the experimental data on Figure 4. It is important to point that the product of decomposition is an amorphous solid that does not evolve into crystal phases (Figure 5). This amorphous compound is made up of iron hydroxide with absorbed arsenate. Figure 6 is an SEM-EDS image of a partially decomposed particle (20\%), showing an unreacted core, a reaction front, and a gel halo.

Figure 7 presents the energy-dispersive X-ray microanalysis of the particle shown in Figure 6, with an unreacted core and decomposition product (gel halo). In the unreacted core one can observe the typical intensities of the elements in arsenic jarosite (K, Fe, Si and As). However, it can also be seen that the intensities 
of potassium and sulphur of the decomposition gel have practically disappeared, leaving only the intensity peaks of iron, oxygen and arsenic. In this image, the peak corresponding to chlorine was attributed to the water used to wash these partially decomposed solids. Figure 8 corroborates the data demonstrated previously. Observe how $\mathrm{Fe}, \mathrm{O}$, and As remain evenly distributed throughout the particle, indicating that for partially or totally decomposed particles these elements are invariable, which could have favourable implications in the stabilization of arsenic under the experimental conditions herein studied. It can also be noted that $K$ and $S$ in the gel halo diffused into the bulk of the solution, which is consistent with the stabilization zone in Figure 4.

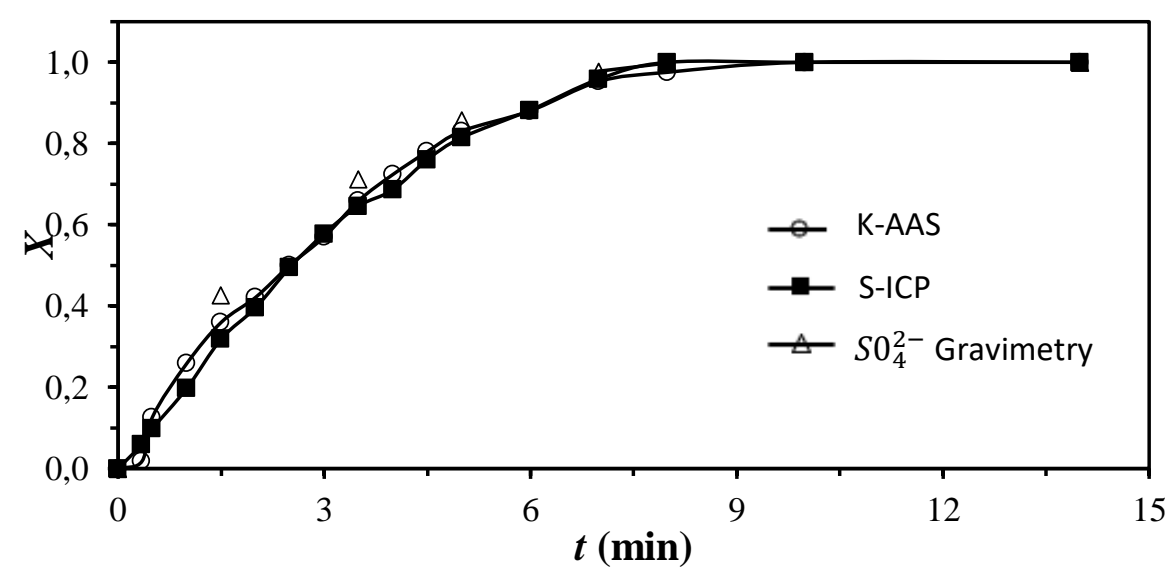

Figure 4 Alkaline decomposition curve

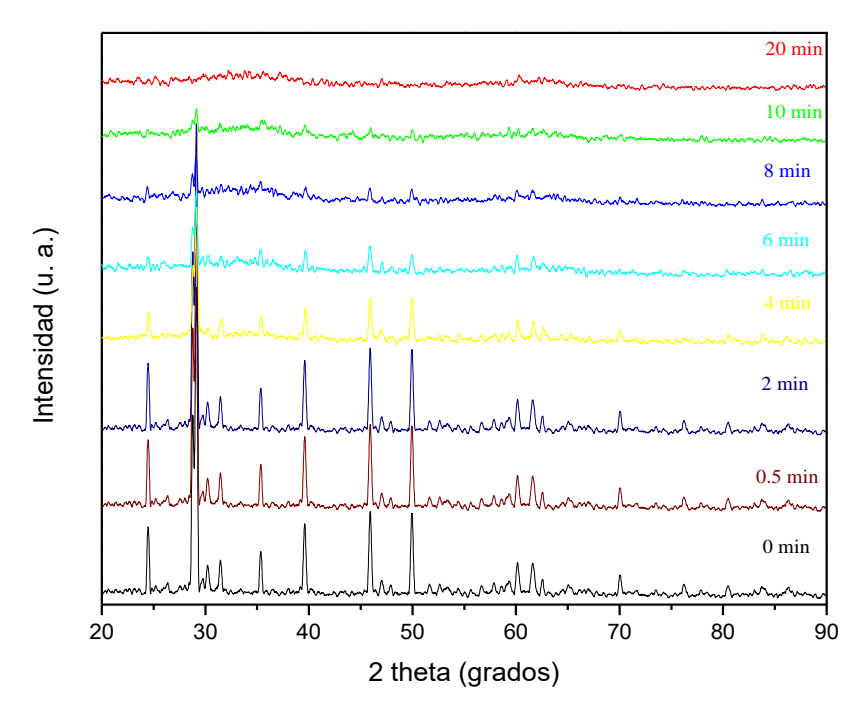

Figure 5 Different decomposition times in $\mathrm{NaOH}$ medium

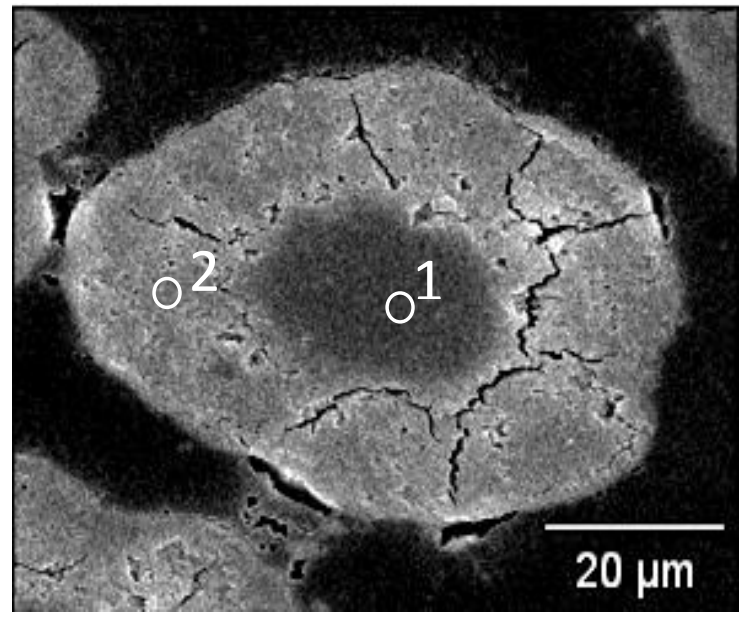

Figure 6 Partially decomposed particle

According to the previously discussed, one can assume that $\mathrm{OH}^{-}$ions of the solution diffuse through the particle, thus establishing a reaction front, while $\mathrm{SO}_{4}{ }^{2-}$ ions diffuse from the particle into the bulk of the solution. As the reaction front progresses towards the centre of the spherical particle, the amorphous gel or ash layer increases, while the core of the potassium-arsenic jarosite tends to disappear. The size and shape of the spherical particle remain constant. Such evidence observed in Figures 6, 7, and $\mathbf{8}$ is consistent with the alkaline decomposition curve of Figure 4 , as well as with the X-ray diffraction graph of the decomposition products on Figure 5. 

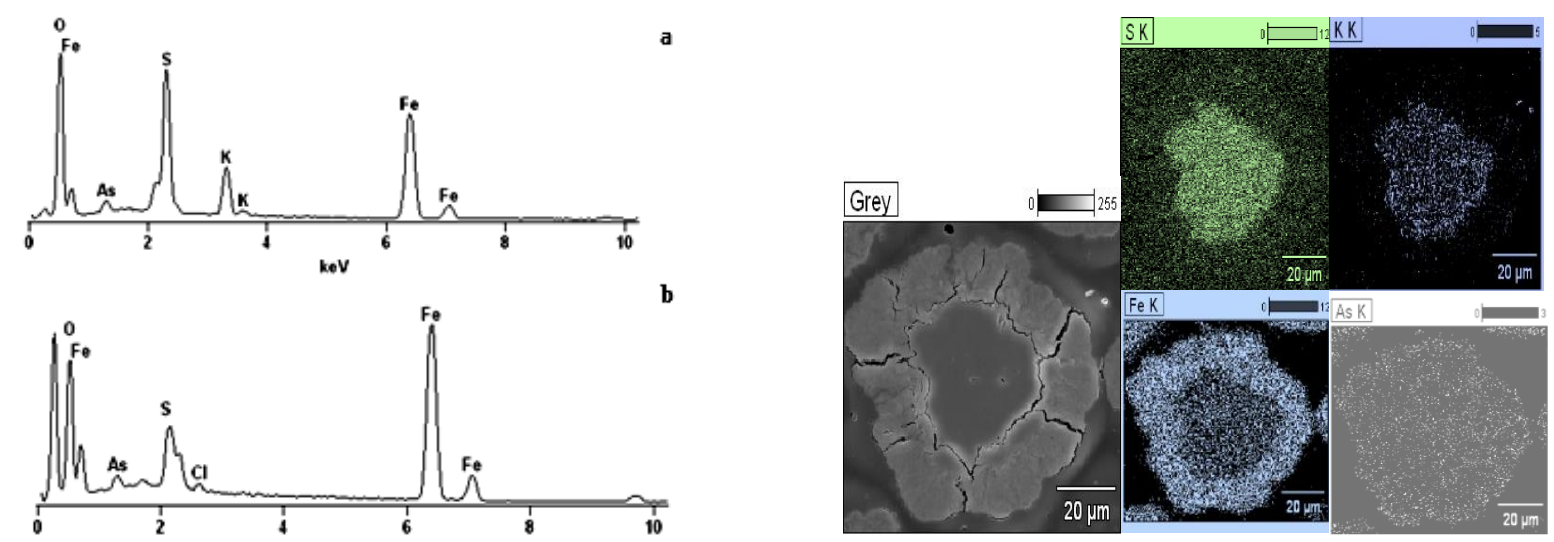

Figure 7 a) EDS of original particle; b) EDS of partially decomposed particle

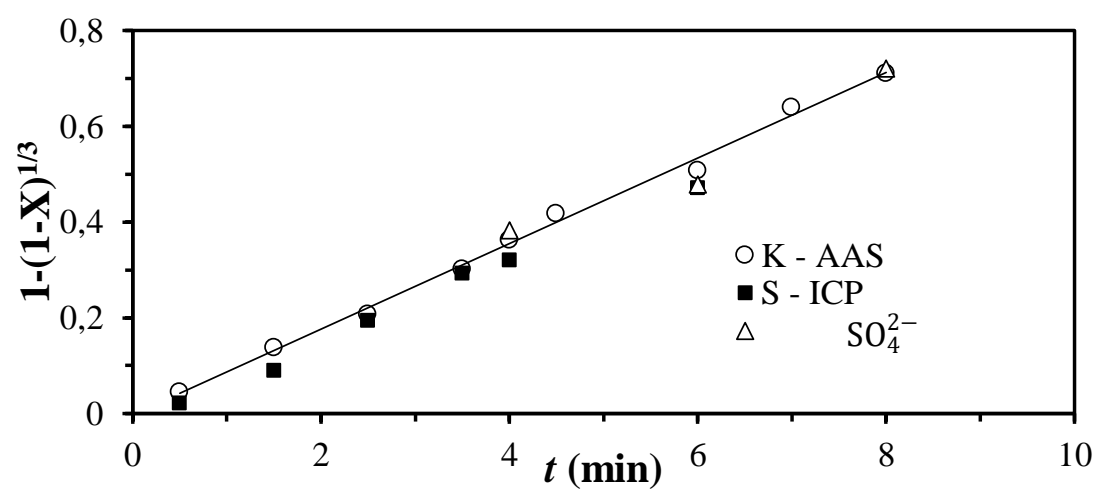

Figure 9 Shrinking core model of constant size spherical particles with chemical control for the decomposition of potassium-arsenic jarosite in $\mathrm{NaOH}$ medium

Figure 9 shows how experimental data of the decomposition of potassium-arsenic jarosite in $\mathrm{NaOH}$ medium are satisfactorily consistent with the kinetic shrinking core model of constant size spherical particles with chemical control. These experimental data are the base for conducting a kinetic study on the alkaline decomposition of this compound under a wide range of experimental conditions, such as $\mathrm{NaOH}$ concentration, temperature, and particle size, with the aim of modelling and establishing the partial and total kinetic expressions of the decomposition process.

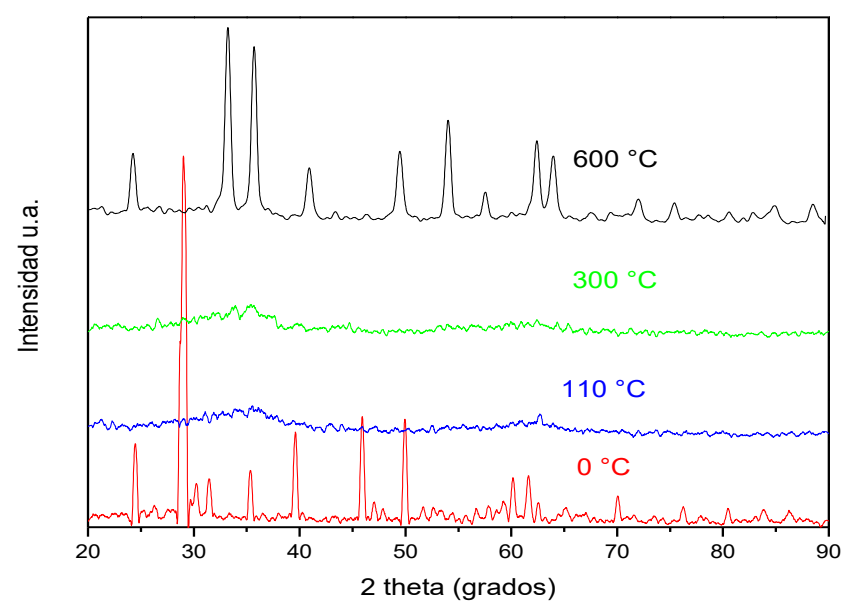

Figure $10 \mathrm{X}$-ray diffraction of the decomposition solids exposed to high temperatures 
It can be appreciated from Figure 10 that the totally decomposed solids exposed to 110 and $300{ }^{\circ} \mathrm{C}$ remained unaltered as an amorphous compound. However, when reaching $600{ }^{\circ} \mathrm{C}$, they evolved into a hematite-type crystal phase $\left(\mathrm{Fe}_{2} \mathrm{O}_{3}\right)$, while arsenic sublimed. It is recommended to study the total decomposition solids at temperatures between 350 and $550{ }^{\circ} \mathrm{C}$ to pinpoint the temperature of sublimation of arsenic contained in the amorphous gel. According to the results, the stoichiometry of the alkaline decomposition process can be expressed by the following reaction:

$\left[\mathrm{K}_{0.75}\left(\mathrm{H}_{3} \mathrm{O}\right)_{0.25}\right] \mathrm{Fe}_{1.84}\left[\left(\mathrm{SO}_{4}\right)_{1.82}\left(\mathrm{AsO}_{4}\right)_{0.18}\right]\left[(\mathrm{OH})_{2.34}\left(\mathrm{H}_{2} \mathrm{O}\right)_{3.66}\right](\mathrm{s})+3.43 \mathrm{OH}_{(\mathrm{aq})} \rightarrow 0.75 \mathrm{~K}^{+}{ }_{(\mathrm{aq})}+1.82 \mathrm{SO}^{2-}{ }_{4(\mathrm{aq})}+1.84$ $\mathrm{Fe}(\mathrm{OH})_{3} 0.18 \mathrm{AsO}_{4}{ }^{3-}{ }_{(\mathrm{gel})}+4.16 \mathrm{H}_{2} \mathrm{O} \ldots .$.

These results are important because:

1) The reaction product of potassium-arsenic jarosite retains arsenic in the decomposition gel, avoiding the diffusion of this toxic metal towards the environment, which makes potassium-arsenic jarosite a potential medium for the stabilization of arsenic.

2) During the roasting process of the amorphous decomposition gel in the range between 110 and $300{ }^{\circ} \mathrm{C}$, arsenic remains retained. This property of retaining arsenic in the decomposition gel makes of potassium jarosite a safe compound for the stabilization of arsenic under severe temperature conditions.

\section{CONCLUSIONS}

The experimental data of the decomposition at $30^{\circ} \mathrm{C}, 0.50 \mathrm{M} \mathrm{NaOH}$ (Figure 4) show an induction period, a progressive conversion period and a stabilization zone of sulfates. The experimental data of the decomposition curve are satisfactorily consistent with the kinetic shrinking core model for constant size spherical particles where the chemical reaction controls the process. The stoichiometry of the reaction of potassium-arsenic jarosite in $\mathrm{NaOH}$ medium indicates the release of $\mathrm{K}^{+}, \mathrm{SO}_{4}{ }^{2-}, \mathrm{H}_{2} \mathrm{O}$, and the formation of an amorphous gel made of iron hydroxide with absorbed arsenate. During the roasting process of the amorphous gel resulting from the decomposition, arsenic in the form of arsenate remains absorbed in that amorphous mass. However, we observed that arsenic sublimes at $600{ }^{\circ} \mathrm{C}$, and the iron gel evolves into a hematite-type crystal phase.

\section{REFERENCES}

[1] DUTRIZAC, J.E., JAMBOR, J.L., AND O'REYLLY, J.B. Man's first use of jarosite: The pre-roman mining-metallurgical operations at Rio Tinto, Spain. Canadian Mining and Metallurgical Bulletin. 1983, vol. 76, no. 859, pp. 78-82.

[2] SCHEMPP, C.A. Argento-jarosite, a new silver mineral. American Journal of Science. 1923, vol. 6, no. 31, pp. 73-74.

[3] PATIÑO C., F. Cinética de la cianuración de argentojarosita y sus soluciones sólidas con plumbojarosita (doctoral thesis). Barcelona, España. Universitat de Barcelona, Facultad de Química. 1991, p. 5.

[4] DUTRIZAC, J.E., JAMBOR, J.L. Formation and characterization of argentojarosite and plumbojarosite and their relevance to metallurgical processing. In: Applied Mineralogy.W.C. Park. AIME. Warrendale, P.A., 1984, pp 507-530.

[5] ARREGI, V., GORDON, A.R., STEINTVELT, G. The jarosite process past, present and future. In: Lead-Zinc-Tin'80. TMS-AIME. New York, 1979, pp. 97-123.

[6] PAMMENTER, R.V., HAIGH, C.J. Improved metal recovery with the low contaminant jarosite process. In Proc. Extraction Metallurgy '81. London: Institute of Mining and Metallurgy, 1981, pp. 379-392.

[7] DUTRIZAC, J.E., KAIMAN, S. Synthesis and properties of jarosite compounds. The Canadian Mineralogist. 1976, vol. 14, no. 2, pp. 151-158.

[8] FLORES, M. U., PATIÑO C., F., REYES, I. A., RIVERA, I., REYES, M., AND JUÁREZ, J.C. Kinetic modelling of the alkaline decomposition of potassium argentojarosite. Journal of the Brazilian Chemical Society. 2012, vol. 23, no. 6, pp.1018-1023.

[9] PATIÑO, F., VIÑALS, J., ROCA, A., NÚÑEZ, C. Alkaline decomposition-cyanidation kinetics of argentian plumbojarosite. Hydrometallurgy. 1994, vol. 34, no. 3, pp. 279-291.

[10] LIDE, D.R. In: LIDE, D.R. Handbook of chemistry and physics. Chapter 8, 89 th ed. Boston: CRC press, 2009. 